\title{
Correlation between erythrocyte sedimentation rate and C-reactive protein level in patients with rheumatic diseases
}

\author{
Anna Kotulska, Magdalena Kopeć-Mędrek, Anida Grosicka, Monika Kubicka, Eugeniusz J. Kucharz \\ Department of Internal Medicine and Rheumatology, Medical University of Silesia, Katowice, Poland
}

\begin{abstract}
Objectives: Erythrocyte sedimentation rate (ESR) and serum level of C-reactive protein (CRP) are the acute phase reactants most commonly determined in patients with rheumatic diseases. The indices are affected by different factors, but both of them are applied for evaluation of the disease activity in patients with inflammatory disorders of the musculoskeletal system.

Material and methods: The authors compared the results of ESR and CRP, which were carried out during routine diagnosis in 200 patients admitted to the Department of Rheumatology.

Results: A significant correlation between ESR and CRP was found (ESR after $1 \mathrm{~h} / \mathrm{CRP}$ : correlation coefficient 0.6944, ESR after $2 \mathrm{~h} / \mathrm{CRP}$ : correlation coefficient 0.6126). There was no difference in ESR or CRP between male and female patients, and patients older than 40 years had higher ESR and CRP. Conclusions: The obtained results support the usefulness of both indices in the clinical practice of rheumatologists.
\end{abstract}

Key words: erythrocyte sedimentation rate, C-reactive protein, rheumatic diseases.

\section{Introduction}

The erythrocyte sedimentation rate (ESR) is the oldest acute phase index. The phenomenon was described by John Hunter [1] and applied as a laboratory test by Edmund Biernacki [2]. Erythrocyte sedimentation rate was probably the most commonly used laboratory test in the $20^{\text {th }}$ century. Currently, the clinical usefulness of ESR is questioned, and the C-reactive protein (CRP) level is widely applied. C-reactive protein was discovered in 1930 by William S. Tillet and Thomas Francis, and the test has experienced a revival in the last two decades due to the discovery of the role of inflammation in atherosclerotic disease [3, 4].

Despite the diminished role of ESR in modern diagnostics, the test is still used in rheumatology. Moreover, some disease activity indices are based on either ESR or CRP. This applies to the indices DAS and DAS28 used to determine activity of rheumatoid arthritis [5].

The comparative value of ESR and CRP in measuring disease activity was investigated in groups of patients with certain rheumatic disorders. De Vries et al. [6] reported that ESR and CRP (as well as serum amyloid A) were significantly associated with the Bath Ankylosing Spondylitis Activity Index in 15155 patient with ankylosing spondylitis, and the ESR association was the strongest. The erythrocyte sedimentation rate and CRP are found to be sensitive markers of disease activity in patients with rheumatoid arthritis, as reviewed by Ruof and Stucki [7]. The juvenile arthritis disease activity score is calculated using ESR or CRP, and Nordal et al. [8] found that results of both ways of calculation of the score lead to very similar results. Thus they recommended both of them for assessing disease activity in patients with juvenile idiopathic arthritis. Several other reports indicate similar alterations in ESR and CRP in various diseases including systemic lupus erythematosus (SLE) [9] and rheumatoid arthritis (RA) [10, 11].

The present study was designed to determine the correlation of ESR and CRP in patients admitted to the rheumatologic ward due to various rheumatic disorders.

Address for correspondence:

Eugeniusz J. Kucharz, Department of Internal Medicine and Rheumatology, Medical University of Silesia, Katowice, Poland,

e-mail: ejkucharz@poczta.onet.pl

Submitted: 10.07.2015; Accepted: 19.09.2015 


\section{Material and methods}

We evaluated the results of the documentation of 200 patients admitted consecutively to the Department of Internal Medicine and Rheumatology in Katowice who were routinely diagnosed. The patients suffered from various disorders, but all of them represented more severe cases than average patients with rheumatic disease, because most of the patients remained under care of the out-patient clinics.

The characteristics of the investigated patients are summarized in Table I. In all patients ESR and CRP were determined at admission with routine methods. The

Table I. Characteristics of patients

\begin{tabular}{|ll|}
\hline Characteristic feature & \multicolumn{1}{c|}{ Result } \\
\hline Male/female & $51(25.5 \%) / 149(74.5 \%)$ \\
\hline Age (years) (mean \pm SD) & $48.0 \pm 14.1$ \\
\hline $\begin{array}{l}\text { Duration of overt disease } \\
\text { (years) (mean } \pm \text { SD) }\end{array}$ & $6.1 \pm 5.3$ \\
\hline
\end{tabular}

Table II. Erythrocyte sedimentation rate and C-reactive protein and their correlation in all the patients

\begin{tabular}{|lc|}
\hline Indice & Results $(x \pm$ SD) \\
\hline ESR1 $(\mathrm{mm} / 1 \mathrm{~h})$ & $25.3 \pm 21.4$ \\
\hline ESR2 $(\mathrm{mm} / 2 \mathrm{~h})$ & $50.5 \pm 31.4$ \\
\hline CRP $(\mathrm{mg} / \mathrm{l})$ & $18.7 \pm 28.9$ \\
\hline $\begin{array}{l}\text { correlation ESR1/CRP } \\
\text { (correlation coefficient) }\end{array}$ & 0.6944 \\
\hline $\begin{array}{l}\text { correlation ESR1/CRP } \\
\text { (correlation coefficient) }\end{array}$ & 0.6126 \\
\hline $\begin{array}{l}\text { correlation ESR1/ESR2 } \\
\text { (correlation coefficient) }\end{array}$ & 0.9524 \\
\hline
\end{tabular}

erythrocyte sedimentation rate was measured after the $1^{\text {st }}$ and $2^{\text {nd }}$ hours (denoted as ESR1 and ESR2, respectively).

\section{Results}

The erythrocyte sedimentation rate and CRP in all the patients and correlations of the indices are shown in Table II. As expected, enhanced ESR1, ESR2 and CRP were found in the patients. A significant correlation between ESR (both ESR1 and ESR2) and CRP was found. Additionally, a very strong correlation of ESR1 and ESR2 was observed, but it reflects the nature of the ESR phenomenon. In Table III, the patients are divided into subgroups. It was found that the values of ESR and CRP were very similar in female and male patients. Patients older than 40 had higher ESR and CRP.

The most common groups of patients in the investigated cohort were those with RA (60 patients), SLE (25 patients), and systemic sclerosis (19 patients). The next groups of the patients were those with ankylosing spondylitis (17 patients) and systemic vasculitis other than granulomatosis with polyangiitis (formerly Wegener's granulomatosis) (16 patients).

\section{Discussion}

The erythrocyte sedimentation rate is a physical phenomenon related to plasma viscosity and the number of red cells. Plasma viscosity, or more precisely the albumin/globulin ratio, is altered in an acute phase reaction and is probably the most significant factor affecting ESR. An additional factor which influences ESR is serum fibrinogen level [12]. The test is simple and very cheap. C-reactive protein is an acute-phase protein belonging to the highly conserved pentraxin family. C-reactive protein is synthesized in the hepatocyte and its

Table III. Erythrocyte sedimentation rate and C-reactive protein in subgroups of the patients

\begin{tabular}{|c|c|c|c|c|c|}
\hline Subgroup of the patients & ESR1 & ESR2 & CRP & ESR1/CRp & ESR2/CRP \\
\hline male & $26.0 \pm 18.3$ & $52.1 \pm 28.7$ & $20.0 \pm 24.9$ & 0.7057 & 0.6756 \\
\hline female & $25.1 \pm 22.4$ & $49.9 \pm 32.3$ & $18.3 \pm 30.2$ & 0.6916 & 0.5970 \\
\hline aged $<40$ years & $21.5 \pm 18.9$ & $43.7 \pm 28.3$ & $14.3 \pm 20.7$ & 0.6608 & 0.3911 \\
\hline$>41$ years & $27.1 \pm 22.3$ & $53.7 \pm 32.4$ & $20.9 \pm 30.0$ & 0.7057 & 0.6775 \\
\hline $\begin{array}{l}\text { systemic lupus } \\
\text { erythematosus }\end{array}$ & $31.2 \pm 33.2$ & $55.6 \pm 43.9$ & $19.3 \pm 38.8$ & 0.8634 & 0.8476 \\
\hline rheumatoid arthritis & $23.9 \pm 19.6$ & $49.8 \pm 31.0$ & $17.0 \pm 30.6$ & 0.6318 & 0.6091 \\
\hline $\begin{array}{l}\text { systemic vasculitis (other } \\
\text { than granulomatosis with } \\
\text { polyangiitis) }\end{array}$ & $26.5 \pm 23.9$ & $52.4 \pm 35.3$ & $15.9 \pm 33.9$ & 0.6146 & 0.5859 \\
\hline ankylosing spondylitis & $30.6 \pm 7.1$ & $59.6 \pm 16.1$ & $26.7 \pm 12.4$ & 0.9229 & 0.8384 \\
\hline systemic sclerosis & $23.0 \pm 16.3$ & $49.6 \pm 26.5$ & $26.4 \pm 31.3$ & 0.7358 & 0.6666 \\
\hline
\end{tabular}


transcription is mainly regulated by interleukin-6. Biological functions of CRP are partially known and include activation of complement via the classical pathway and contribution to opsonization and phagocytosis of some microorganisms as well as clearance of necrotic cells [3].

Our studies did not reveal any difference in the investigated acute phase reactants between female and male patients. Studies on early RA showed that female patients had higher ESR [12]. It is concomitant with other findings that ESR tends to be more elevated in women than in men [13]. There is no generally accepted agreement on sex difference in serum CRP level. Some reports suggested higher values in men [14], while others revealed opposite results [15]. Our studies are concomitant with findings indicating higher ESR and CRP in older patients [12]. It is important to take this into consideration, because the disease activity calculated on the basis of acute phase reactants might be overestimated.

Despite different factors affecting ESR and CRP, a significant positive correlation between the tests was found in all investigated patients and especially in those with ankylosing spondylitis and SLE. In patients with SLE, the correlation between ESR and CRP is not so clear, and the elevation of inflammatory markers is considered to be a factor associated with a poorer prognosis [16]. In the present study, the group of SLE patients was relatively small and as mentioned above showed a strong positive ESR and CRP correlation. Among the patients studied there were no patients with Sjögren's syndrome, but it is known that in this autoimmune disease with hypergammaglobulinemia the ESR is often increased without clinical signs and without a significant increase of CRP, and these patients have not been taken into account.

The obtained results support the view of concomitant application of ESR and CRP in calculation of the disease activity indices in certain disorders, including rheumatoid arthritis, juvenile idiopathic arthritis and ankylosing spondylitis. This finding is concomitant with the suggestion of Kay et al. [17] to obtain both ESR and CRP from rheumatoid arthritis patients at the initial visit. An association of acute phase reaction and radiographic progression of the disease in these patients has also been reported [18]. Similar observations were made in patients with spondyloarthropathies, but the range of the acute reaction in these patients was generally lower [19].

\section{Conclusions}

In summary, the performed analysis confirmed the usefulness of both ESR and CRP in the clinical practice of rheumatologists, but understanding of different un- derlying mechanisms leading to enhanced test results should always be taken into consideration.

The authors declare no conflict of interest.

\section{References}

1. Madrenas J, Potter P, Cairns E. Giving credit where credit is due: John Hunter and the discovery of erythrocyte sedimentation rate. Lancet 2005; 366: 2140-2141.

2. Kucharz EJ. Edmund Biernacki and the erythrocyte sedimentation rate. Lancet 1987; 329: 696.

3. Ablij H, Meinders A. C-reactive protein: history and revival. Eur J Intern Med 2002; 13: 412-422.

4. Kucharz EJ. Chronic inflammation-enhanced atherosclerosis: Can we consider it as a new clinical sysndrome? Med Hypotheses 2012; 78: 396-397.

5. Bijsma JW. Optimal treatment of rheumatoid arthritis: EULAR recommendations for clinical practice. Pol Arch Med Wewn 2010; 120: 347-353.

6. de Vries MK, van Eijk IC, van der Horst-Bruinsma IE, et al. Erythrocyte sedimentation rate, C-reactive protein level, and serum amyloid A protein for patient selection and monitoring of anti-tumor necrosis treatment in ankylosing spondylitis. Arthritis Rheum 2009; 61: 1484-1490.

7. Ruof J, Stucki G. Validity aspects of erythrocyte sedimentation rate and C-reactive protein in ankylosing spondylitis: a literature review. J Rheumatol 1999; 26: 966-970.

8. Nordal EB, Zak M, Aalto K, et al. Validity and predictive ability of the juvenile arthritis disease disease activity score based on CRP versus ESR in a Nordic population - based setting. Ann Rheum Dis 2012; 71: 1122-1127.

9. Amezcua-Guerra LM, Springall R, Arrieta-Alvarado AA, et al. $C$-reactive protein and complement components but not-other acute-phase reactions discriminate between clinical subsets and organ damage in systemic lupus erythematosus. Clin Lab 2011; 57: 607-613.

10. Hamdi W, Néji O, Ghannouchi MM, et al. Comparative study of indices of activity evaluation in rheumatoid arthritis. Ann Phys Rehabil Med 2011; 54: 421-428.

11. Silva I, Mateus M, Branco JC. Velocidade de sedimentação on proteina $C$ reactiva. Que variaveis utilizar na avaliacao clinica dos doentes com artivite reumatóide? Acta Reumatol Port 2010; 25: 456-462.

12. Siemons L, ten Klooster PM, Vonkeman HE, et al. How age and sex affect the erythrocyte sedimentation rate and C-reactive protein in early rheumatoid arthritis. BMC Musculoskeletal Dis 2015; 15: 368-374.

13. Shearn MA, Kang IY. Effect of age and sex on the erythrocyte sedimentation rate. J Rheumatol 1986; 13: 297-298.

14. Lee YJ, Lee JH, Shin YH, et al. Gender difference and determination of C-reactive protein level in Korean adults. Clin Chem Lab Med 2009; 47: 863-869.

15. Piéroni L, Bastard JP, Piton A, et al. Interpretation of circulating C-reactive protein levels in adults: body mass index and gender are a must. Diabetes Metab 2003; 29: 133-138. 
16. Gafter-Gvili A, Leibovici L, Molad Y. Elevation of inflammatory markers in patients with systemic lupus erythematosus is as sociated with poorer outcome. Biomed Pharmacother 2013; 67: 48-52.

17. Kay J, Morgacheva O, Messing SP, et al. Clinical disease activity and acute phase reactant levels are discordant among patients with active rheumatoid arthritis: acute phase reactant levels contribute separately to predicting outcome at one year. Arthritis Res Ther 2014; 16: R40.

18. Navarro-Compán V, Gherghe AM, Smolen JS, et al. Relationship between disease activity indices and their individual components and radiographic progression in RA: a systematic literature review. Rheumatology 2015; 54: 994-1007.

19. Chen $\mathrm{CH}$, Chen HA, Liao HT, et al. The clinical usefulness of ESR, CRP, and disease duration in ankylosing spondylitis: the product of these acute-phase reactants and disease duration is associated with patient's poor physical mobility. Rheumatol Int 2015; 35: 1263-1267. 